IOS Press

\title{
Foundation for Physical Medicine \& Rehabilitation announces 2016 winners of the Gabriella E. Molnar-Swafford Pediatric PM\&R Awards
}

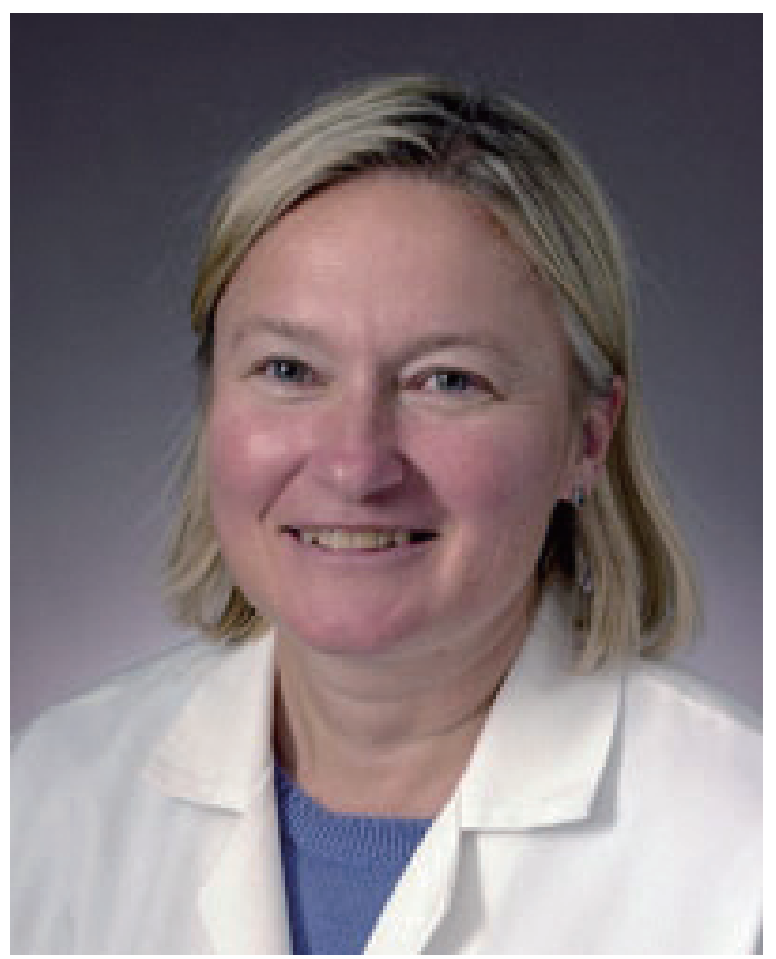

\section{Gabriella E. Molnar-Swafford Pediatric PM\&R Lifetime Achievement Award}

Linda Joyce Michaud (August 12, 1951-October 5, 2015) is the Gabriella E. Molnar-Swafford Pediatric PM\&R Lifetime Achievement Award winner. Sadly, this award honoring her dedication to the field of pediatric physiatry is being given posthumously.

Dr. Michaud began her academic career as an Assistant Professor in the Department of Pediatrics at the Children's Hospital of Philadelphia in the early 1990's. In 1997, Cincinnati Children's Medical Center recruited her to lead a newly formed Division of
Rehabilitation Medicine. Over the following 16 years, Dr. Michaud grew this young division into one of the country's largest divisions of pediatric rehabilitation medicine with national recognition for its clinical, research, and educational missions. Dr. Michaud recruited five additional academic faculty over the years. Her division benefited from 100 percent faculty retention under her leadership. She developed many new clinical programs, including the Brachial Plexus Program that served as a model for interdisciplinary collaboration and evidence-based care. She took part in the training of over 30 residents and fellows.

Dr. Michaud had a strong commitment to service. She helped promote and advance the science of the young specialty of pediatric rehabilitation medicine, serving on a variety of boards and important scientific committees. She served on the Editorial Board of Journal of Head Trauma Rehabilitation and as Guest Editor for Journal of Pediatric Rehabilitation Medicine. She served in Armenia, Poland, and Russia as physician advisor for Project Hope, an organization that provided pediatric rehabilitation care to earthquake survivors.

Dr. Michaud had a strong fondness for the book From Good to Great, promoting it throughout most of her career at Cincinnati. The book describes the importance of a B.H.A.G. or a Big Hairy Audacious Goal. "Linda's B.H.A.G. was to create a nationally prominent division of pediatric rehabilitation at Cincinnati Children's Hospital Medical Center and she succeeded. I am certain that Linda would approve of our division's new B.H.A.G., which is to transform our understanding and management of pediatric brain injury," wrote Mary McMahon, M.D., Aaron W. Perlman Chair of Pediatric Rehabilitation Medicine at Cincinnati Children's Hospital Medical Center in her letter nominating Dr. Michaud for this lifetime achievement award. Most recently, Dr. Michaud was a pediatric physiatrist and the Director of Pediatric PM\&R Research for Spaulding Rehabilitation Network/Spaulding Cape Cod. 
Dr. Michaud gave more than 90 national and international presentations and is widely published in numerous medical journals. She had a strong passion for education and learning new things. As was tradition in the early years of pediatric physiatry, she completed independent pediatric and $P M \& R$ residencies. She was a research fellow in injury prevention and control at the University of Washington. In addition to her medical degree, Dr. Michaud obtained a B.S. in Physical Therapy, a M.Ed. in Early Childhood Special Education, and a Masters of Rehabilitation Medicine.

\section{Gabriella E. Molnar-Swafford Pediatric PM\&R Research Grant Recipient}

Yuxi Chen of Montefiore Medical Center is the Gabriella Molnar Pediatric PM\&R Research Grant winner for the project "Assessing the Efficacy of Virtual Reality Analgesia (VRA) in Pediatric Patients for Pain Control During Botulinum Toxin Injections (BTI) for Spasticity Management." Dr. Chen received her medical degree in China and completed a fellowship in pediatric rehabilitation at Montefiore Medical Center. Dr. Chen is Assistant Professor in Department of Pediatrics and Department of Physical Medicine and Rehabilitation at Albert Einstein College of Medicine. 